Provided for non-commercial research and education use. Not for reproduction, distribution or commercial use.

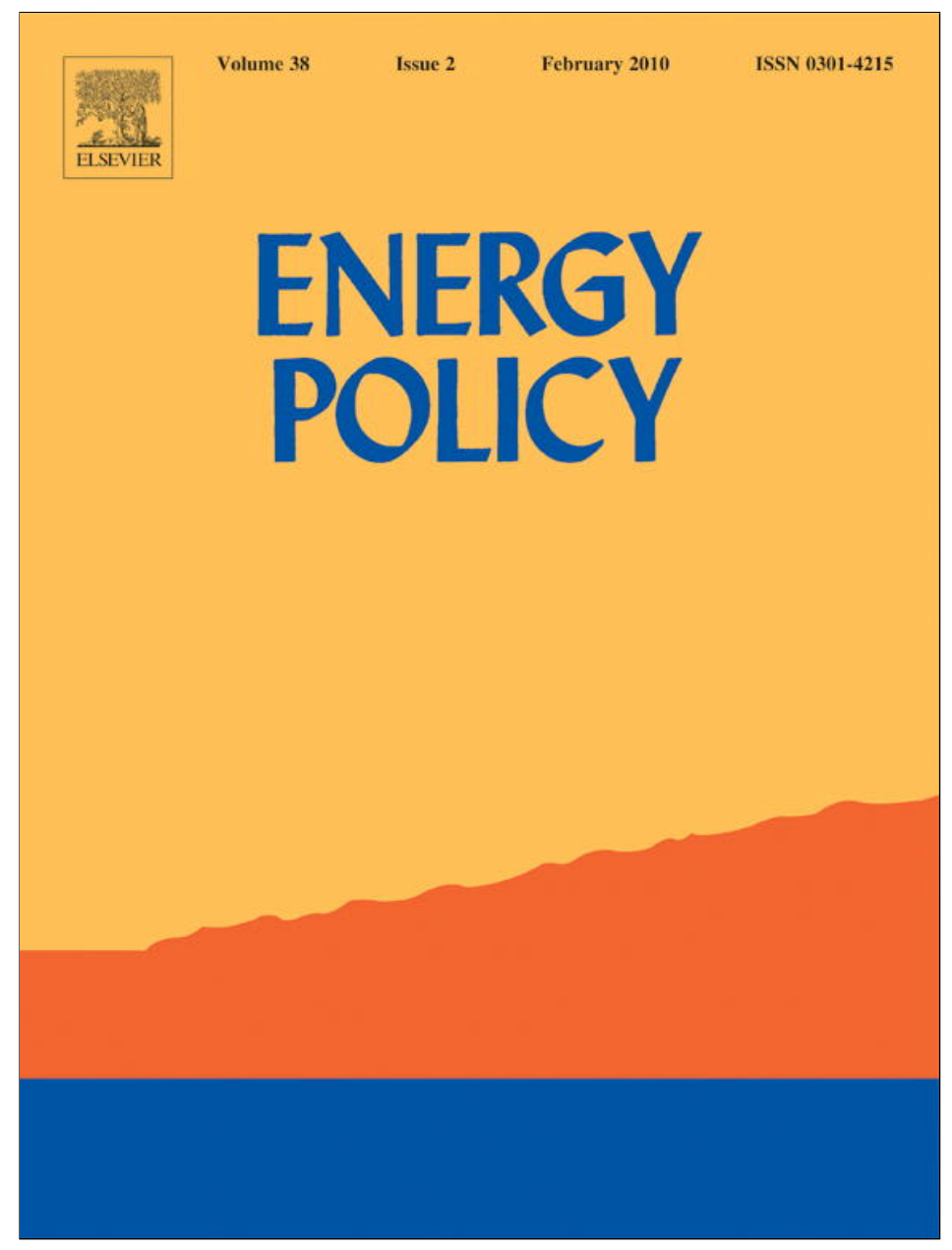

This article appeared in a journal published by Elsevier. The attached copy is furnished to the author for internal non-commercial research and education use, including for instruction at the authors institution and sharing with colleagues.

Other uses, including reproduction and distribution, or selling or licensing copies, or posting to personal, institutional or third party websites are prohibited.

In most cases authors are permitted to post their version of the article (e.g. in Word or Tex form) to their personal website or institutional repository. Authors requiring further information regarding Elsevier's archiving and manuscript policies are encouraged to visit:

http://www.elsevier.com/copyright 


\title{
Alternative Australian climate change plans: The public's views
}

\author{
Richard T. Carson ${ }^{\mathrm{a}, \mathrm{b}, *}$, Jordan J. Louviere ${ }^{\mathrm{b}}$, Edward Wei ${ }^{\mathrm{b}}$ \\ a Department of Economics, University of California, San Diego, La Jolla, CA 92093, USA \\ ${ }^{\mathrm{b}}$ Centre for the Study of Choice, University of Technology, Sydney, P.O. Box 123, Broadway, NSW 2007, Australia
}

\section{A R T I C L E I N F O}

\section{Article history:}

Received 27 May 2009

Accepted 19 October 2009

Available online 13 November 2009

Keywords:

Climate policy

Discrete choice modeling

Preference heterogeneity

\begin{abstract}
A B S T R A C T
Climate change has come to the forefront of Australian politics and there is now an active on-going policy debate about how to best reach a commonly agreed long term goal. This paper looks at five major dimensions of this debate and constructs policy options based on them. A discrete choice experiment approach was used with a representative sample from a major internet panel provider. Survey respondents made choices between pairs of policy options with different characteristics. They favored policies starting in 2010 rather than 2012, and spending 20\% of revenue raised on energy-related R\&D. They were almost evenly split on whether the plan should initially exempt the transport sector and two competing approaches that redistribute revenue from the plan, and, they opposed plans giving special treatment to energy-intensive sectors of the economy. A number of other policy relevant questions related to understanding Australian views and knowledge related to climate change also were asked.
\end{abstract} (c) 2009 Elsevier Ltd. All rights reserved.

\section{Introduction}

Australia may be the first country where environmental policy and climate policy, in particular, played a dominant role in a national election. The Australian Labour party won the national parliamentary election on November 242007 defeating the Liberal/National Coalition which had been in office for 12 years. The three major issues in the election according to opinion surveys were the government's policy toward worker rights, climate policy and water policy, with the latter two linked by a very severe drought. Symbolically, the first official act of Kevin Rudd on becoming Prime Minister was to ratify the Kyoto Protocol.

Since then Rudd opened debate over specific features of the policy and strongly indicated that he wants a bipartisan consensus. As might be expected, political pundits and a wide spectrum of interest groups and experts soon weighed in along with opposition parties. Ministers and shadow ministers discussing climate change are a fixture on TV news shows. There are frequent commentaries in the press by academics, environmentalists, politicians, business leaders and well-known political commentators. As often happens, competing forces have greatly slowed the process by expressing their views of what is in the public interest.

The Australian Government has mounted a non-partisan effort to get the Australian public actively engaged in the debate over

\footnotetext{
* Corresponding author at: Department of Economics, University of California, San Diego, La Jolla, CA 92093, USA. Tel./fax: +1 858534 3383/7040.

E-mail address: rcarson@ucsd.edu (R.T. Carson).
}

climate policy. In this report, we measure the public's views on an Australian climate change plan through a comprehensive opinion survey of Australians using a stated preference framework (Louviere et al., 2000). In reality, there is often not one policy but rather a large number of policies each of which assembles different components in various ways. This paper provides an examination the public preferences toward the key elements that make up such policy options in a framework that forces respondents to make explicit tradeoffs regarding alternative policy packages, with the policy packages designed to represent stylized versions of the ongoing debate. Two key features of our study are that the costs/drawbacks of various options are clearly disclosed to respondents, something often ignored by advocates of particular positions and in most public opinion polls, and an examination of the degree of the heterogeneity in the strength of the public's preferences toward the key policy elements when forced to make tradeoffs. The paper also presents results from a number of other survey questions important to understanding the climate policy in Australia from the public's perspective.

\subsection{The Australian climate change political environment}

The Liberal Party under Prime Minister John Howard signed and originally indicated a willingness to ratify Kyoto after negotiating major concessions for Australia that involved allowing an 8\% increase in emissions from 1990 to 2012, and substantially increasing the baseline by 33\% to account for changes in "land clearing". On June 5 (World Environment Day) 2002, the Howard government, in the face of strong and continuing opposition by Australia's powerful coal industry, 
announced that it would not ratify Kyoto. By the 2007 election, the battles lines were drawn with the Labour Party and the Green Party, Australia's third largest party, clearly supporting immediate and strong action to reduce greenhouse gas emissions. The Liberal Party, recognizing the unpopularity of its position moderated it somewhat, indicating a willingness to join a second round of Kyoto after 2012 if other major emitters did. It was clear that there was a major split within the party over climate issues. After losing the national 2007 election, Howard retired, and the Liberal Party indicated a willingness to again go forward with a substantive climate policy. Within that party a succession battle ensued between Brendan Nelson, initially named party leader, who largely supported Howard's views on climate change, and Malcolm Turnbull, perhaps the strongest proponent within the Liberal Party for moving forward on climate change. After a leadership vote, Turnbull became party leader.

Labour, while previously out of power at the national level, controlled all eight state and territory-level governments. The party commissioned Garnaut, a senior Australian economist at Australian National University and an advisor to former Labour governments as well as Australian Ambassador to China, to head a large effort to make recommendations on climate policy. This mechanism was transferred to the national government when Labour assumed power, with various government ministries (particularly, Treasury) actively involved in the process. Garnaut issued a series of interim reports on different issues, culminating in a final report (2008) at the end of September 2008; this report had many similarities but also some important differences to the Stern Report in Great Britain (Stern, 2007). This review process gave the new Labour government the ability to act fairly quickly on a major complex policy; and the series of interim reports by Garnaut helped engender an ongoing public discussion of policy options.

One of the most important facets of the current Australian climate policy debate is agreement by all major parties to move forward on a substantive plan. The ruling Labour party, in contrast to its position on employment policies, has clearly signalled that it wants a consensus plan. There is also reasonably broad agreement on achieving at least a $60 \%$ reduction in emissions by 2050 through the use of marketable pollution permits. There was much less agreement on what the other key features of Australia's climate policy should look like.

\subsection{Policy options}

The Australian debate over climate change has been farranging. Our objective is to let people choose between potential climate policies, each of which can be seen as a bundle of a relatively small number of attributes. To construct these climate policies we first determine which attributes are of interest, and then how a policy can vary along that attribute. To help determine candidates for the attributes, we consulted the various Garnaut reports and did an extensive review of media coverage.

The most obvious candidate for an attribute was the start date of the climate policy. Here the Labour and Liberal party leaders had staked out clear differences with Labour (and the Green Party) pushing for a 2010 start date and the Liberals (along with the National Party) pushing for a 2012 start date. Both start dates are capable of achieving the same 2050 goal with reasons (particularly symbolic ones) to start earlier and reasons (usually linked to ease of adjustment and the possibility of getting broader agreement, particularly from China) to start later. Unspoken in much of the debate is the fact that a 2010 start date would involve lower annual costs but paying over two more years than a 2012 start date. We are interested in making tradeoffs such as this apparent to people when choosing between alternative policies.

Another obvious candidate for an attribute is what to do with revenues raised from carbon permits. Here one senses that the Labour Party saw the need to adopt a climate policy, and fully embraced this once it realized the potential to use the revenues to further long term goals of redistributing income toward low income households and seniors. In contrast, the Liberal Party saw the cost of reducing greenhouses gases as a major drag on the economy and wanted to see the revenues raised recycled in ways like reducing the GST (Goods and Service Tax, which is a valueadded tax) or various business taxes.

Impacts of climate policy are likely to be most obvious to consumers by way of increases in fuel prices in the transportation sector. The ratification of Kyoto came at a time when oil prices were at near record highs, so it is not surprising that the Labour Party proposed that the transportation sector be initially exempted for the first three years, ostensibly for the purpose of allowing households to adjust to the prospect of higher fuel prices. This exemption was strongly opposed by the Green Party and was inconsistent with Garnaut's recommendations. Of course, the cost of initially exempting the transportation sector is that the entire burden of the climate plan would fall on other sectors.

Not surprisingly, the other sectors of the economy likely to bear the brunt of higher carbon prices have pushed for special treatment. Labour and Liberal Party leaders (but not the Greens) have had a sympathetic ear for Australia's big energy-intensive exporters, farmers, and, somewhat surprisingly, electric power generators. Proposals for special treatment are varied, ranging from initial exemptions to free permits.

The Garnaut reports (2008) strongly urged the government to set aside $20 \%$ of the revenue from carbon permits for research and development activities. Prior public opinion surveys (e.g., $B B C, 2007$ ) showed strong public support to include R\&D in any climate plan. Short-run costs occasionally have been mentioned in surveys involving renewable energy and energy efficiency, and many people seem to think that such programs will reduce long-term costs (e.g., WorldPublicOpinion.org, 2008). These survey questions, however, do not make it clear to households that putting money into R\&D implies less revenue returned to households to help offset the impacts of higher energy prices.

Thus, the aforementioned five key attributes of climate policy are studied in a discrete choice experiment (DCE). Other potential attributes of Australia's climate policy are studied by separate individual questions. One of these is the basic question of whether someone favors adopting any climate policy. (This is an option apparently not "on the table", as all major parties seem committed to some type of action.) However, it is useful to know how widely held this position is, and whether the public favors going forward with a plan irrespective of other countries' actions. The major parties seem committed to moving forward, but the issue of China and the United States also committing to reductions has loomed large in the public debate; and some have argued that Australia's plan should be conditional on actions by these two countries. Another question we examine as a separate issue is the magnitude of the 2050 objective, with both major parties committed to a $60 \%$ reduction in greenhouse gases. However, the Garnaut reports (2008) suggests the possibility of an $80 \%$ reduction. This position has long been supported by the Green Party and is mentioned as a possibility by some Labour party officials. Lastly, we look at the public's view of marketable carbon permits, a consensus approach to alternative instruments like a carbon tax or technology standards that can achieve the same objectives. 


\subsection{Eliciting the public's views}

In an ideal world, elected representatives would know the preferences for policy alternatives of the citizens they represent. Unfortunately, however, this is rarely the case. Instead, representatives often hear the views of those with the most to gain or lose from how a policy is implemented. This is natural, as these parties have incentives to invest resources to influence a legislative outcome. Public opinion polls often appear in the press but cover only a few questions that typically provide little substantial information about policy options and tradeoffs. A far more nuanced view of the public's preferences can be obtained through a special purpose survey focused on posing the difficult tradeoffs legislators face when crafting a broad policy like one dealing with climate change where there are many options.

Although elected to "represent" constituents, there has been a longstanding debate as to the extent to which political representatives understand voter preferences for alternative policies or the degree to which they take these preferences into account when proposing policies or voting on them (e.g., Stewart and Gelherd, 1976; Page and Shapiro, 1983; Stimpson et al., 1996). Voter preferences may not be clear-cut because they may have to tradeoff one or more aspects of a proposed policy to obtain other aspects. For example, one can have more parks in an urban area, but this typically requires funds to be allocated and spent. In turn, this implies either that some other publically provided services will be cut or additional revenue must be raised. So, citizens who want more parks may have to give up more libraries; while citizens who want more libraries may have to give up more parks. This example illustrates the dilemma facing elected representatives, namely knowing that voters want more parks is not the same as knowing that they are willing to give up libraries to get them. As the number of policy dimensions increases, naively predicting how the public will make such tradeoffs becomes increasingly difficult, suggesting the need for a more sophisticated approach than a typical traditional public opinion survey to help policymakers gauge where the public stands.

\subsection{Prior literature}

There is now a substantial literature on public opinion relating to climate change, much of this in the form of public opinion surveys reported in the press. ${ }^{1}$ An academic literature also exists that examines more specialized issues. An early paper using an ethnographic approach is Kempton (1991), which tries to understand how U.S. citizens conceptualize the problem. A paper with a psychological orientation looking at many of the same issues is Read et al. (1994). Comparing public opinion across countries also has been a popular topic (Dunlap, 1998). This literature has become increasingly sophisticated over time, and attempts to address a number of factors that underlie support for climate change policies, such as age (Hersch and Viscusi, 2006), environmental beliefs and risk perceptions (O'Connor et al., 1999), personal vulnerability to impacts (Zahran et al., 2006) and degree of understanding of climate change and the nature of the impacts likely to happen to the respondent (O'Connor et al., 2002).

There also is a literature that explicitly tries to understand the public's willingness to pay for different aspects of climate change using a contingent valuation approach starting with Berk and Schulman's (1995) pioneering work. This paper and a subsequent paper (Berk and Fovell (1999)) include several improvements to scenarios offered to respondents to make them more realistic.

${ }^{1}$ Many of the major studies are available at www.pollingreport.com in the energy and environment sections.
They used telephone surveys combined with a fractional factorial design to try to understand willingness to pay to avoid various temperature and precipitation impacts in the greater Los Angeles area. Cameron (2005a, 2005b) looked at the role of subjective expectations and updating of information in willingness to pay for mitigating climate change. Layton and Brown (2000) look at willingness to pay to prevent adverse forest impacts, with particular emphasis on modeling heterogeneity in respondent preferences. Berrens et al. (2004) used an internet-based sample and Lee and Cameron (2008) used a mail survey to study various methodological issues related to measuring willingness to pay for the United States joining Kyoto. Lee and Cameron also examined some specific policy issues, such as how willingness to pay in the United States changes if other countries are seen to be involved in efforts to reduce climate change. Riera et al. (2007) examine willingness to pay to avoid climate induced adverse impacts on specific types of Mediterranean landscapes. Lee et al., forthcoming provide a recent application in South Korea that shows that willingness to pay to prevent climate change increases with education and income.

Our study adopts an approach consistent with the policy referenda variant of contingent valuation that Kopp and Portney (1999) argue is needed to consider climate change policies. The approach adopted also has similarities to the public opinion literature that focuses on gauging the desirability of particular aspect of a policy. A key distinction is that we specifically include costs and ask respondents to make tradeoffs with clear economic interpretations. Further, instead of looking at willingness to pay to avoid specific physical climate change impacts, we look at how people choose between policies with different characteristics that achieve the same long-term (2050) objective in different ways. These characteristics of policies, such as the nature of the payment, have long been seen as something that theoretically can influence preferences toward policies, and hence, willingness to pay estimates are always conditional on how a policy is implemented. Yet, most economists act as if this does not matter. Interestingly, with very localized siting disputes, there is more willingness by economists (e.g., Opaluch et al., 1993) and other social scientists (e.g., Firestone and Kempton, 2007) to look at specific implementation issues as the source of the conflict.

The purpose of this paper is to examine the public preferences toward "implementation details" and the strength of those preferences when forced to make tradeoffs in an important situation where the major parties have agreed in principle to the long-run "objective" and where there are many possible ways in which that objective can be achieved.

\section{Discrete choice experiments for policy alternatives}

Any policy can involve multiple dimensions. There is a varied nomenclature for these dimensions, such as "variables", "characteristics", or "attributes". We use the term "attribute", which is the term most commonly used in the DCE literature (Louviere et al., 2000; Bateman et al., 2002). Consider a simple example like a change to the current income tax code, which might involve changes in (a) income brackets, (b) rates of tax that apply to each bracket, (c) whether there are exemptions for particular activities or expenditures, and if so what types, and/or (d) whether there are exemptions for particular types of people. In turn, each of these attributes can take on a large number of "levels". For example, one attribute level for income brackets might be $[0-25$, $25-100,100+]$ while another level might be $[0-15,15-50,50+]$. Likewise, levels for the rates applied to each tax bracket might be $[0 \%, 10 \%, 20 \%],[0 \%, 15 \%, 30 \%]$, or $[5 \%, 10 \%, 20 \%]$. As the number of attributes and their levels increase, the number of distinct policies 
that represent various combinations of them becomes very large. Thus, it is a "big ask" of any elected representative to know what proportion of voters might choose each of the policy options. Unfortunately, however, without information about voter choices, a representative must guess and/or get information from lobbyists who purport to represent particular interests.

\subsection{Climate policy as a bundle of attributes}

The main focus of the survey was a series of specially designed questions that asked respondents to choose between different climate change policies for Australia. Any climate policy can be viewed as a combination or bundle of attributes. The attributes of potential policies can be identified from the positions that the major political parties take as reported by various media sources. These attributes include the year the emission trading starts, how to return any revenue generated, whether to initially exempt the transport sector, whether to invest in an R\&D program, and whether energy intensive sectors should receive special treatment. Obviously, more attributes can be identified; however, we wanted to keep the experimental design manageable and make differences in policy options easy to see and understand.

Each of the above five attributes can take on various values called "levels". Again, the main levels that we considered were identified from published media reports. We minimized the possible number of levels to allow us to examine the main outlines of the debate. These levels are shown below:

1. The year that the emissions trading program will start (2010 or 2012) and the associated cost with starting in that year;

2. How to redistribute revenues generated by the plan (reduce the GST or give it to low income households and seniors);

3. Whether to invest some revenues generated by the plan in $R \& D$ (invest in R\&D or lower taxes);

4. Whether transport-related industries should be exempted (yes or no); and

5. Whether energy-intensive industries should receive special treatment (yes or no).

The first tradeoff involved a start date of 2010 versus 2012 . Starting later was assumed to involve households facing $20 \%$ higher costs to compensate for the later start date, given the need to achieve the same 2050 objective. Respondents were informed about the increase in fuel costs, electricity costs and overall prices associated with the two start dates. That is, the cost of a plan can be characterized by an increase in fuel prices ( 5 vs. 6 cents per litre), an increase in electricity prices (16\% vs. $20 \%$ ), and an overall increase in the prices $(0.9 \%$ vs. $1.1 \%)$ of goods and services that people consume. The second tradeoff was how to distribute revenue raised by a plan. The two main options were a general reduction of the GST from $10 \%$ to $9 \%$, or returning the revenue to low income households and seniors who would be most impacted. The third tradeoff involved whether or not to invest $20 \%$ of revenue raised in $R \& D$ intended to reduce energy consumption. Investment in R\&D holds out the hope of reducing future costs, but if one chooses this option there is proportionately less money to return to households. The fourth tradeoff involved whether to initially exempt the transport sector for three years. This action would give people time to adjust their vehicle holdings and travel choices; however, it is not costless as other prices would increase more due to a smaller reduction in the transport sector. The last tradeoff involved whether to give special treatment to energy intensive industries for the first three years of the plan; these industries were defined as electric utilities, exporters who use lots of energy, and farmers. Respondents were told this would give these sectors more time to adjust and reduce job disruption, with the drawback being that it would force the rest of the economy to cut back more in the early years of the plan and return less money to households.

Hopefully, it now is clear that there is not ONE policy, but instead several potential policies represented by different combinations of attribute levels. For example, here are two:

Policy 1: Start the plan in 2010, use the revenues to lower taxes, distribute the revenues by using them to reduce the GST, exempt transport-related industries, and do not give special treatment to energy-intensive industries.

Policy 2: Start the plan in 2012, use the revenues to invest in $R \& D$, distribute the revenues by giving them to low income households and seniors, do not exempt transport-related industries, and give special treatment to energy-intensive industries.

The two combinations/bundles of attribute levels above are two of the possible combinations. All possible combinations are given by multiplying the number of levels of all attributes with one another, which is called a "factorial expansion". Thus, the number of possible combinations is $2 \times 2 \times 2 \times 2 \times 2$, or 32 . In fact, these combinations represent what is known as a "complete factorial design" in the literature on the design of statistical experiments (e.g., Box et al., 1978). Ideally, we would like to offer all possible pairs of plans to voters and let them choose which one(s) they want their elected representatives to enact. In this case, there are $(32 \times 31) / 2=496$ pairs, a daunting number. It is unrealistic to expect that voters would be able to express 496 choices, much less that they would agree to or even want to do this. Thus, one needs a way to reduce the size of the problem that is feasible to implement in a survey.

One solution to this problem is to take a "purposive" sample from all the possible pairs that guarantees certain statistical properties in advance, rather than leave things to chance by taking a random sample. Such purposive samples are called "fractional factorial designs". Statistical theory is available for choosing a sample to optimize certain properties (Street and Burgess, 2007). In our case, we used one orthogonal main effects plan to make eight pairs of plans that insure we can estimate voter preferences for each attribute independently of one another; then we made a mirror image of that design to create eight more plans (known as the "foldover" of the original design). This design does not allow us to reliably estimate all of the twoway interaction terms, although inclusion of the identified interactions does not appear to substantially change the general nature of the findings we report. Together the two designs insure that all main effects are independent of unobserved but potentially significant two-factor interactions; so each respondent received 16 of the possible 496 pairs, and the levels of each policy attribute in each pair are mirror images of one another. That is, one policy always has a start year of 2010 and the other a start year of 2012; all other attributes are similarly contrasted. This particular way of constructing choice pairs forces people to make tradeoffs because they have to give up some potentially desirable attribute levels to get more preferred levels of other attributes. One can now clearly see that it is difficult to anticipate the proportion of voters who will prefer each policy in each of the 16 pairs because different people will have different preferences for the attributes/levels of the plans.

Having only 16 distinct choice sets limits the nature of the analysis that can be conducted. To increase the range of policy alternatives that can be examined, the first attribute a respondent saw was always the start date/cost attribute but then only three of the four other attributes used in the DCE were displayed. We randomly assigned different sets of 16 choice sets to statistically equivalent subsets of respondents using a multi-stage YoudenWilliams design blocked by the set of attributes seen. The order of 
the 16 choice sets seen within a block was also systematically varied within - and between - respondents to ensure the same mix of choice sets was administered at each of the 16 orders in the sequence.

The highly "balanced" nature of our design allows one to estimate the standard logistic choice model but also intentionally allows a much simpler type of analysis. Indeed, all one needs to do to make statements about our sample's preferences is to count the fraction of times a policy with a particular alternative level (e.g., a 2010 versus a 2012 start date) is chosen by each person. One can measure heterogeneity and strength of preferences merely by constructing the frequency distribution of how many times an alternative level was chosen by respondents. Respondents for whom a particular attribute level is very important relative to other levels usually will choose a policy with that attribute level irrespective of the level of other attributes. To see how this works, note that each respondent was given a sequence of 16 questions that asked for a choice between two plans comprised of different policy elements. The binary attributes in each question were balanced so that each level appears an equal number of times and in such a manner that the attributes are orthogonal to each other. It is straightforward to show in this case that all of the aggregate information on sample preferences can be recovered from the counts on how many times particular attribute levels were chosen. This information represents the sufficient statistics for the estimation of the standard random utility models. ${ }^{2}$ This approach is a non-parametric alternative to random coefficients/ mixed logit models, the results of which can be sensitive to distributional assumptions made about preference heterogeneity.

\subsection{Data collection}

We designed and administered a survey to a sample of 768 randomly chosen respondents during the week of 11 August 2008. Respondents were drawn from a large on-line internet panel of individuals maintained by PureProfile, an Australian-based online panel provider. The panel is selected to match Australian demographic characteristics with respect to state of residence, age and gender. The sample is representative of those with access to the internet, which is over $80 \%$ of the Australian population. Relative to the Australian population as a whole, very low income individuals, older seniors, and those in rural areas are somewhat under-represented in the panel. Results are weighted to be reflective of the age, gender, and state residence. The effect of the weighing are small, though with the unweighted results differing from the weight results by no more than a couple percentage points. Respondents were asked three types of questions:

1. A set of questions that asked them to choose between two emission trading plans. Each plan differed on a series of policy elements that required respondents to make tradeoffs among the policy elements.

2. A second set of questions that asked them for their views on climate change and environmental issues.

3. A third set of questions that asked them to provide demographic information.

Marginal counts (frequencies) for responses to the main questions are in Appendix A. The description of attribute levels for the DCE and an example choice set are in Appendix B. The 16 choice sets for each of the 768 respondents yield 12,288 binary

\footnotetext{
${ }^{2}$ We are currently working on extending this framework to cover more general cases.
}

Table 1

Preferences over policy elements.

\begin{tabular}{|c|c|c|}
\hline Policy element & $\begin{array}{l}\text { First option (\% in } \\
\text { favour) }\end{array}$ & $\begin{array}{l}\text { Second option (\% in } \\
\text { favour) }\end{array}$ \\
\hline Start date & $2010(57.1 \%)$ & $2012(42.9 \%)$ \\
\hline Revenue distribution & Reduce GST (48.6\%) & $\begin{array}{l}\text { Low income/seniors } \\
(51.4 \%)\end{array}$ \\
\hline Invest $20 \%$ in $R \& D$ & Yes $(58.8 \%)$ & No $(41.2 \%)$ \\
\hline Transport sector & Initially exempt (50.7\%) & Don't exempt (49.3\%) \\
\hline $\begin{array}{l}\text { Sector special } \\
\text { treatment }\end{array}$ & Yes $(46.3 \%)$ & No $(53.7 \%)$ \\
\hline
\end{tabular}

choices between policy options. The survey instrument intentionally did not provide a "don't know" or "no-choice" option in order to encourage respondents to make policy choices. However, we did include questions on respondent knowledge and perceived levels of uncertainty about climate change. The response rate of those accepting the invitation to participate in the survey was $76.5 \%$.

\section{Results}

Australians clearly believe that global warming is happening (84.3\%). A very large majority of respondents rejects the idea of not adopting a plan to reduce greenhouse gases (82.6\%); and a large majority believes that Australia should go ahead and cut its greenhouse gases regardless of what other countries do $(84.7 \%)^{3}$ A sizeable majority of respondents (65.7\%) views global warming as either an extremely serious problem (34.7\%) or a very serious problem (31.0\%). Another $21.4 \%$ see global warming as a problem, with only $7.0 \%$ seeing it as slightly serious and $6.0 \%$ seeing the problem as not at all serious. Respondents see even greater climate-related problems for developing countries with $45.8 \%$ seeing extremely serious problems and another $28.3 \%$ seeing very serious problems.

Table 1 displays the basic findings from the tradeoff exercise whereby respondents chose between plans with different policy elements. All of differences between the options for different policy elements are statistically significant at $p<.01$ except for the transport sector options which is significant at $p<.10 .{ }^{4}$ With respect to the choice of start date, 2010 was more popular (57.1\%) than 2012. Respondents had a slight preference (51.4\%) for redistributing revenue to low income households and seniors rather than reducing the GST and were almost evenly split over whether to initially exempt the transport sector. over how to redistribute revenue from the plan and whether to exempt the transport sector. There was a clear majority (58.8\%) in favour of investing $20 \%$ of the revenue from the plan in $R \& D$ and a smaller majority (53.7\%) in favour of not giving special treatment to energy intensive sectors.

It is also possible to look at heterogeneity in strength of preference across respondents with respect to different attributes. Recall that a respondent always can choose a policy with a desired attribute level but potentially at the expense of getting less desired levels on other attributes. The balanced nature of our design allows us to examine this heterogeneity simply by looking

${ }^{3}$ This wording was taken from a Sydney Morning Herald Poll (21 July 2008) "Do you think Australia should press ahead and cut its greenhouse gas emissions, regardless of what other countries do?" The results of that question (which allowed a do know response) was: $77 \%$ YES, $19 \%$ NO, and 4\% DO KNOW.

${ }^{4} \mathrm{~A}$ conditional logit model effectively reproduces the results in Table 1. A standard mixed logit model does a reasonable job of fitting the heterogeneity of preferences for the five attributes except for revenue redistribution. 
a
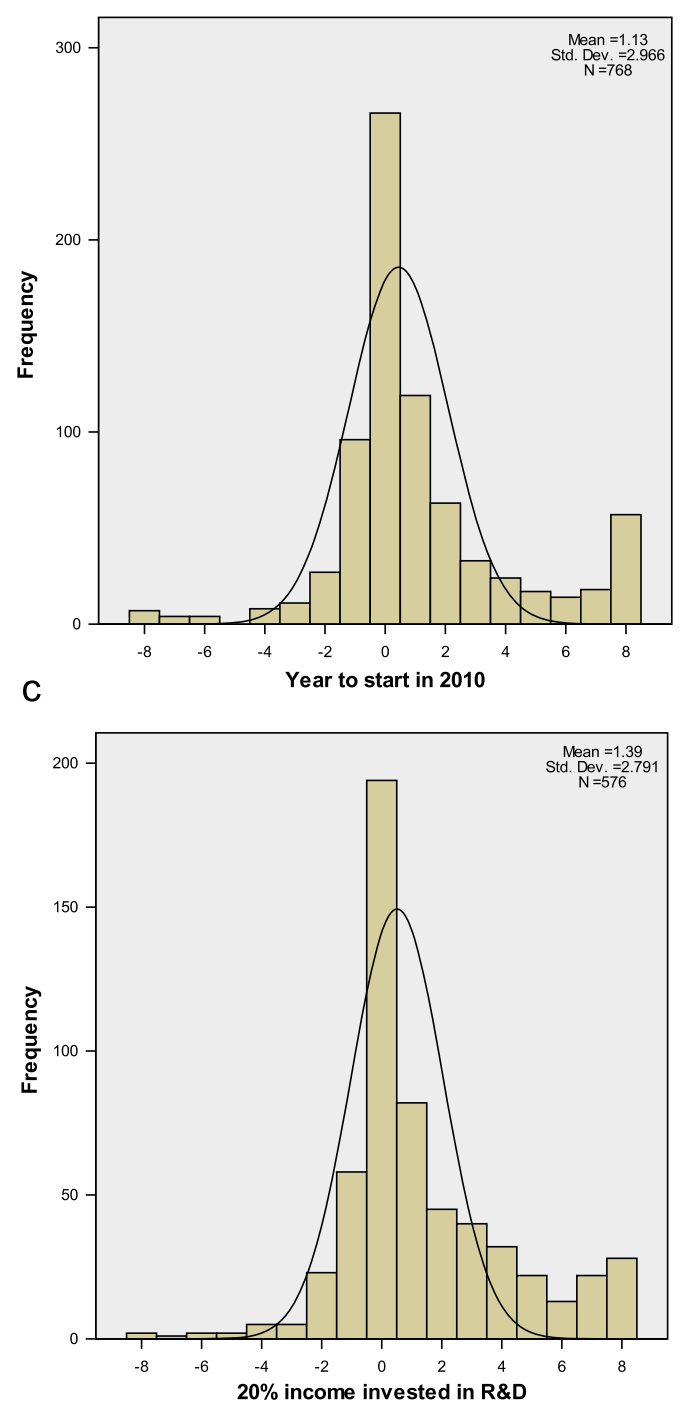

b

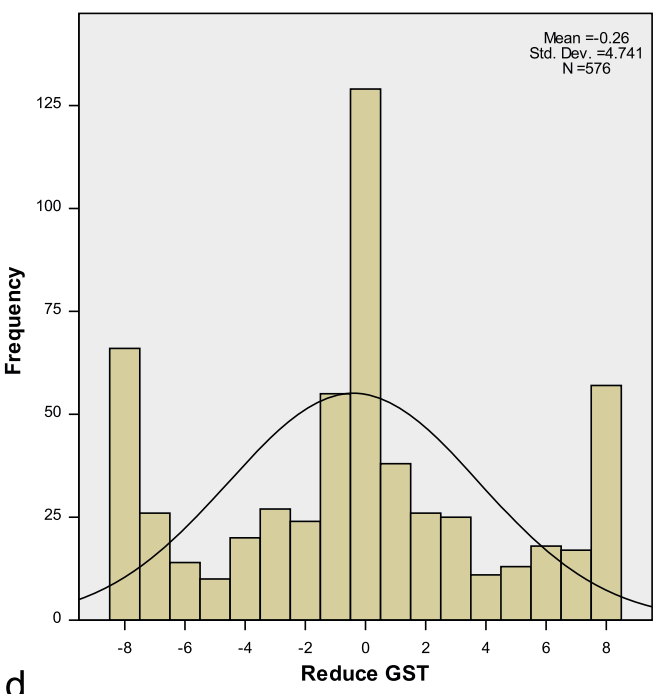

d

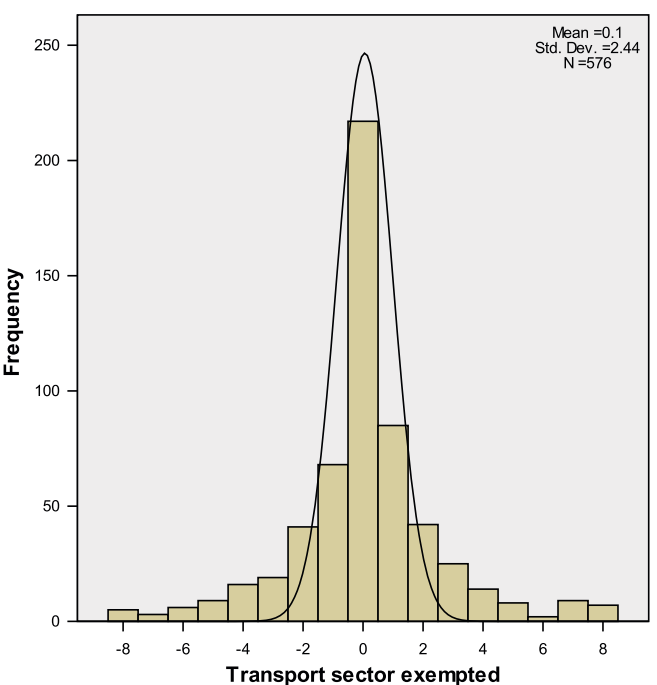

e

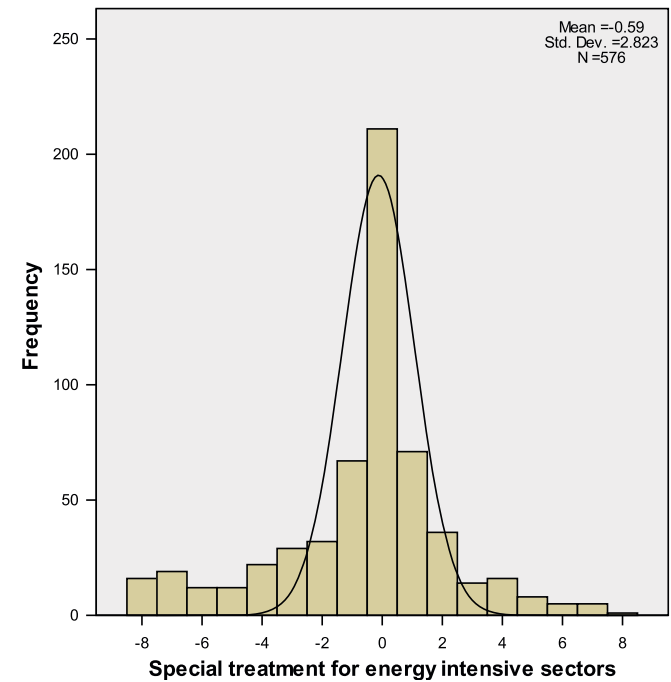

Fig. 1. (a) Histogram for preferring 2010 start date. (b) Histogram for preferring to GST reduction for revenue redistribution. (c) Histogram for preferring to invest $20 \%$ on R\&D expenditures. (d) Histogram for preferring to initially exempt transport sector. (e) Histogram for preferring special treatment of energy intensive sectors. 
at the number of times a particular respondent chose a policy with a particular attribute level. The distribution of the strength of preferences can be obtained by looking at histograms of how many times the first level was chosen for the five attributes. These histograms are show in Figs. 1a-d, where the frequency counts range from -8 (weakest, never chose first level, to 0 (indifferent, chose first and second levels an equal number of times), to 8 (strongest, always chose first level). Similar figures for the second attribute level would be mirror images of the first attribute level.

Looking at Fig. 1a, we see that the mode is at the indifference point. Among those not indifferent, however, those favoring the earlier start date considerably outnumber those favoring the later start date. Further, for a non-trivial fraction of respondents, having the earlier start date is such an important feature of the policy bundle that the respondent always picks a program with the earlier start date, irrespective of what the other attribute levels are.

In Fig. 1b, there is a tri-modal distribution of preference intensity for the manner in which revenue from the program would be returned to the public. While there is a large group who are indifferent, there are also sizeable fractions at both extremes who believe this attribute level outweighs all other considerations. As might be expected, differences here are strongly related to age and income $(p<.01)$. Interestingly, these extremes are consistent with an economic viewpoint of the programs that takes the perspective that the first few years of the program are largely immaterial and that an Australian R\&D effort is largely pointless so that the only thing that matters is how the revenue gets redistributed.

Fig. 1c shows that many respondents are close to indifferent with respect to devoting $20 \%$ of revenue (at their expense) to an R\&D program. Here, however, the sizeable fraction of respondents who support such a policy are not counterbalanced by a group opposed. In Fig. 1d, a somewhat different pattern emerges with respect to initially exempting the transport sector. Here, indifference reigns with relatively few willing to tradeoff preferred levels of other attributes for this one. Interestingly, this is the only attribute for which the commonly used normal distribution provides a reasonably good fit. One interpretation of the result is that for most households, lower gasoline prices for the first three years represent a roughly even trade for higher electricity prices. In Fig. 1e, with respect to opposing special treatment of the energy intensive sectors, most respondents are indifferent or close to indifferent to that point. Opponents outnumber supporters and are generally stronger in the strength of their opposition. However, the asymmetry of the preference strength distribution is not as pronounced on this attribute as it is on R\&D.

It is also possible to examine whether these preferences vary systematically with respondent characteristics. We found minor partisan differences for a preferred start date, with $59.1 \%$ of those identifying with the Labour Party favouring a 2010 start date, $53.0 \%$ of those identifying with the Liberal Party favouring a 2010 start date, and 63.0\% identifying with the Green Party favouring a 2010 start date. There was more of a partisan divide on whether to redistribute the revenue raised largely to low income households and seniors with $55.0 \%$ of Labour identifiers supporting this option but less than majority support from Liberal identifiers (47.7\%). Green and National party identifiers tended to most strongly support giving the revenue to low income households and seniors, with a large block of independent voters being somewhat opposed. There were some large geographic differences: Melbourne and Sydney residents were evenly split, but New South Wales and Victoria residents outside capital cities favored redistributing to low income households and seniors. Australian Capital Territory (Canberra), Adelaide, Brisbane, Northern Territory, and non-Perth Western Australian respondents favored reducing the GST over redistributing revenues, but Perth, Queensland residents outside of Brisbane, South Australian residents outside of Adelaide, and Tasmanian residents held the opposite view. Respondents with incomes of less than $\$ 45,000$ or more strongly favoured (57.0\%) income redistribution while those with incomes of $\$ 45,000$ or more favoured reducing the GST by the same percent (57.3\%). Respondents aged 60 and over strongly favored $(71.0 \%)$ redistributing revenue raised to low income households and seniors. For the transport sector, those with either no cars or three or more cars and those who use public transport six or seven days a week tended to be somewhat less supportive of initially exempting the transport sector but the differences are not large. Differences across states may be more important, as those living in Western Australia where driving distances typically are longer were more supportive (54.7\%) than those in other areas. Those optimistic about technological breakthroughs solving major environmental problems were most favorably inclined toward devoting $20 \%$ of the plan's revenue to energy R\&D. A majority of respondents from all parties were not inclined to give special treatment to energy intensive sectors. Those who identified with the Green Party were less likely (43.7\%) to give special treatment to energy intensive sectors than those identifying with the Liberal Party (48.1\%). Labour and independents fell in between.

Turning now to other questions in the survey, there clearly is room to improve the public's knowledge about global warming. Only $12.6 \%$ of respondents indicated they knew a lot about global warming; $60.1 \%$ indicated that they knew a moderate amount; $26.0 \%$ indicated that they knew little; and 1.3\% indicated that they knew nothing. When we asked respondents how certain they were of their opinions about global warming, $16.3 \%$ stated that they were extremely sure of their opinions, $34.9 \%$ stated that they were very sure, $36.4 \%$ stated that they were somewhat sure, while the remainder stated that they were slightly sure $(8.1 \%)$ or not sure at all (4.3\%). Global warming is an extremely important issue to $20.4 \%$ of respondents and very important to another $32.2 \%$, which suggests that global warming is a key issue for just over half the population. Another $31.0 \%$ feel global warming is a somewhat important issue while the rest stated that global warming either was not too important $(11.7 \%)$ or not at all important (4.1\%).

A majority of respondents (60.0\%) believe that Australia should adopt a plan with more than a $60 \%$ reduction in greenhouse gases even if this would have higher costs. When given a choice between achieving greenhouse gas reductions using marketable pollution permits, taxes, or technology standards, the sample favored technology standards $(57.7 \%)$ over permits $(25.1 \%)$ or taxes $(17.2 \%)$, but they moved $(p<.01)$ toward supporting taxes (22.5\%) [permits (23.7\%) and technology standards (53.8\%)] if we gave them a bit more information about how the different methods work.

\section{Comparison to recent US public opinion on climate change}

Several of the questions used in this survey were taken from a recent $A B C$ NewsPoll (2008). Thus, it may be of interest to contrast the results of this survey with US public opinion, as the two countries for a long time were the only two industrialized nations not to ratify the Kyoto Protocol. Compared to the United States, more Australians believe global warming has been happening ( $84 \%$ vs. $80 \%$ ), is extremely or very important to them personally ( $53 \%$ vs. $46 \%$ ), and are more willing to take action even if other countries don't ( $85 \%$ vs. $68 \%$ ). While this suggests that Australian public opinion may be somewhat more disposed to taking action on climate change, the differences are not large. Perhaps the most 
striking difference between Australian and American public opinion is that it is less polarized from a political party affiliation perspective in Australia. There is usually less than a $10 \%$ difference on issues between those identifying with the Liberal and Green Parties (with Labour and independents falling in between) while in the United States large differences between those identifying with the Democratic and Republican parties on environmental issues is the norm (PEW, 2008). In both the Australian and US case, public support for climate legislation should be seen as a necessary but not sufficient condition. The timing of serious consideration of major climate legislation in both countries appears to be largely driven by when the leaders of a party with a unified position in favour of such legislation come to power.

\section{Some concluding remarks}

Examining the nature of the public's preference toward Australia's climate policy is of importance because there is broad agreement among the political parties on three of the key features: adopting a policy aimed at achieving substantial reductions, a 2050 objective of (at least) a 60\% reduction in greenhouse gas emissions and letting marketable permits play the primary role in achieving that reduction. This broad agreement shifts the debate toward implementation details, over which there is considerable disagreement among the major political parties and the main interest groups. While differences in the ways that a policy can be implemented are often ignored in formal analyses, implementation details have substantial impacts on interested parties and are the focus of much of the actual debate. The public's views often play little role at this stage. By looking at the main options for implementing Australia's climate policy, our study provides a straightforward approach for examining how public support for a policy changes with the set of options that might be adopted.

There is much heterogeneity in the public's preferences toward the key attributes describing any climate plan. There is reasonably strong support with a bit of partisan tinge for Labour's preferred 2010 start date, but it is far from universal. On the issue of how to redistribute revenue from the plan, preferences often are intensely held. Not surprisingly, they are strongly correlated with self-interest and exhibit a much stronger partisan split. Preferences with respect to how revenue from a climate plan are almost tri-modal in nature with a sizeable fraction of the public placing little weight on this attribute and others placing major weight on it, but in different directions. The public is split down the middle on the issue of initially exempting the transportation sector, but for the most part do not have very strong preferences on this issue when they are informed that the tradeoff is higher prices for electricity and other goods. They strongly oppose giving special treatment to energy-intensive sectors even when told that this would give these sectors more time to adjust and minimize job disruptions. However, it should not be surprising that much of the back and forth negotiation in the Australian parliament have been over the treatment of individual energy intensive sectors and sometimes even specific firms, even though policies containing such provision are substantially less preferred by the public. Finally, many members of the public are technological optimists who seem to buy the argument that devoting a substantial fraction of revenue from marketable permits to energy-oriented $R \& D$ will save them money in the long-run even though it may be personally costly in the short-run.

On broader issues related to climate change, it seems clear that Australians are convinced global warming is happening, it is a real problem for Australia and other countries, and Australia should not wait for the United States and China to act. The Australian public's views on these issues show much less political polarization than in the United States. Hence, it was not surprising that the new Labour government signed the Kyoto Protocol as its inaugural act and proposed a strong climate change policy. It also was not surprising to see the Liberal Party reverse its previous position and embrace the same long-term goal in the face of public opinion that clearly had swung against their previous policy of delaying until the United States and other countries acted.

The approach proposed in this paper may be useful in looking at a variety of other energy issues where there is a consensus, either political or court-ordered, on what a policy must achieve in the long-run, but there are multiple options to realizing the same outcome. Surveying the public by offering them a range of policy options can give useful information to policymakers. With the right experimental design, this information is straightforward to convey. Complex models are not required to display the fraction of the public who favour a particular attribute level and the distribution of preference intensities on particular attribute levels in the policy bundle. As always, much of the task is developing the appropriate set of attributes and their levels to adequately describe the main options in a manner that the public can understand.

\section{Acknowledgements}

We would like to thank David Pihlens and participants in seminars at the University of California, San Diego and the University of Washington, Seattle for helpful comments. Jane Pong provided useful research assistance.

\section{Appendix A. Question wording and marginals}

Question: Australia should not adopt any plan to reduce greenhouse gases?

17.4\% YES

$82.6 \% \mathrm{NO}$

Question: Do you think Australia should go ahead and cut its greenhouse gas emissions regardless of what other countries do?

84.7\% YES

$15.3 \% \mathrm{NO}$

Question: Australia should adopt a plan that will result in a larger cutback than the $60 \%$ in greenhouse gas reductions even if this would have higher costs?

60.0\% YES

$40.0 \%$ NO

Question: You may have heard that some people and some scientists think that the world's temperature may have been going up slowly over the past 100 years. We would like to know your personal opinion on this. That is do you think that this has probably been happening or probably has not been happening?

84.3\% Has been

happening

15.7\% Has not been

happening

Question: If nothing has been done to reduce global warming in the future how serious a problem do you think that it will be for Australia? 


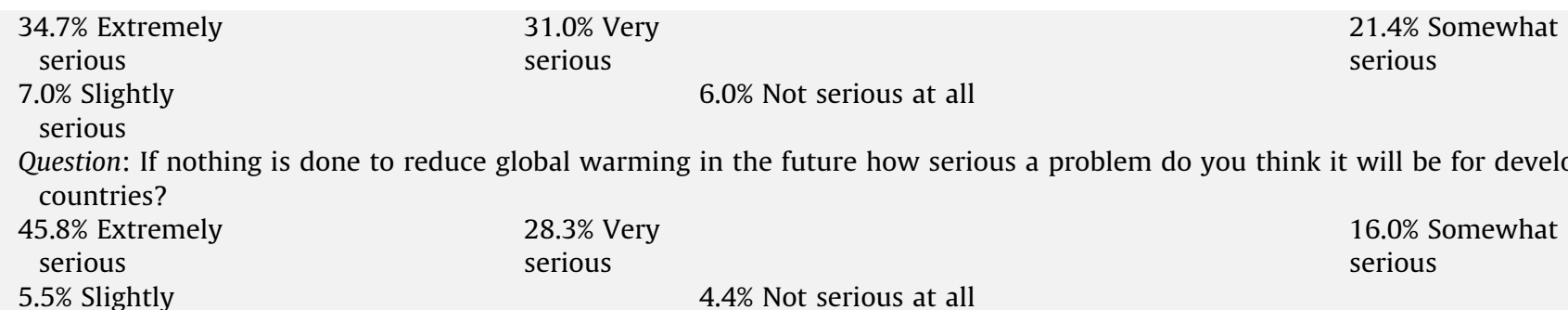

$4.4 \%$ Not serious at all

Question: Previous research suggests that most people know a lot about some issues but very little about others. How much do you

feel you know about global warming?

$\begin{array}{llll}12.6 \% \text { A lot } & \begin{array}{l}60.1 \% \text { A moderate } \\ \text { amount }\end{array} & 26.0 \% \text { A little } & 1.3 \% \text { Nothing }\end{array}$

Question: How important is the issue of global warming to you personally?

20.9\% Extremely $\quad 32.2 \%$ Very

important important

$11.7 \%$ Not too

important

Question: Overall how sure are you of your opinions about global warming?

$16.3 \%$ Extremely $\quad 34.9 \%$ Very sure

sure

$8.1 \%$ Slightly sure $\quad 4.3 \%$ Not sure at

all

31.0\% Somewhat

important

$4.1 \%$ Not at all

important

36.4\% Somewhat

sure

Question: Thinking about your local area if comparing protecting the environment with economic growth and development, which one do you think is more important?

$71.9 \%$

Environment

$28.1 \%$ Economic growth and

development

Question: How much faith do you have that technological breakthroughs will solve the major environmental problems in the future?

$19.5 \%$ A lot $\quad 52.2 \%$ Some $\quad 24.3 \%$ Little $4.0 \%$

None

Question: Which of these [taxes, permits, technical standards] is the way you most prefer the government to use to reduce greenhouse emissions?

$19.0 \%$ Taxes

24.4\% Permits

$55.9 \%$ Technical

Short version: $17.2 \%$ taxes, $25.1 \%$ permits, $57.7 \%$ technical standards

Long version: $22.5 \%$ taxes, $23.7 \%$ permits, $53.8 \%$ technical standards

\section{Appendix B. Survey language on greenhouse gas reduction plans}

Next we will show you 16 sets of TWO possible plans to reduce greenhouse gases. The plans differ in the features described below. All we want you to do is to tell us your most preferred plan in each pair of plans.

As we mentioned, each possible plan is described by different features. These features are as follows:

A. When to start a plan? There are two options currently being proposed by the political parties-starting the plan to reduce greenhouse gases in $\mathbf{2 0 1 0}$ or 2012. Both start dates can achieve a 60\% cutback in greenhouse gases by 2050 . Their start dates differ because a plan starting in 2010 should cost less. The cost of a plan is due to the increase in fuel prices required, the increase in electric prices required, and the overall increase in the price of goods and services that people consume. These costs are shown in the table below.

\begin{tabular}{|c|c|c|c|}
\hline Start year & Fuel price increase & Utility increase & Overall price increase \\
\hline 2010 & 5 cents per litre & $16 \%$ increase & $0.9 \%$ increase \\
\hline 2012 & 6 cents per litre & $20 \%$ increase & $1.1 \%$ increase \\
\hline
\end{tabular}

B. How to give back revenue raised by a plan? Revenue that the government raises from a plan can be used in different ways. One way is simply to return all the revenue to the public by reducing the GST from $10 \%$ to $9 \%$. Another way is to give back most of the money raised to lower income households and seniors who probably will be hardest hit by cost increases. So, the two options are 1) return revenue by Lowering GST or, 2) give the revenues to Low Income Households/Seniors.

C. Whether to heavily invest in R\&D? Another thing that could be done with part of the revenue raised by a plan is to invest $20 \%$ of it in research and development that focuses on reducing energy consumption and greenhouse gas emissions. This might reduce the future costs of controlling greenhouse gas emissions but also would result in $20 \%$ less money to return to the public. So, the two options are "Invest in R\&D" (Yes) or "Don't Invest in R\&D" (No).

D. Should the transport sector initially be exempted? Initially exempting the transportation sector from having to cut back during the first three years of a plan would give people more time to adjust by doing things like buying more fuel efficient cars or finding other ways to get to work. However, a drawback of doing this is that it would further increase utility bills and the costs of other goods purchased. This will happen because the transportation sector is a big source of greenhouse gas emissions, so exempting them would 
Survey on Controlling Greenhouse Gases

\begin{tabular}{|l|c|c|}
\hline Plan Features & Plan A & Plan B \\
\hline $\begin{array}{l}\text { The year that the plan begins (Higher cost with later } \\
\text { start date) }\end{array}$ & 2010 & 2012 \\
\hline $\begin{array}{l}\text { Use } 20 \% \text { of plan income to invest in R\&D to more } \\
\text { cheaply reduce CO2 }\end{array}$ & No & Yes \\
\hline Transport sector initially exempted/included & Yes & No \\
\hline Energy intensive sectors get special treatment & No & Yes \\
\hline
\end{tabular}

The government should implement: (tick one)

c Plan A

c Plan B

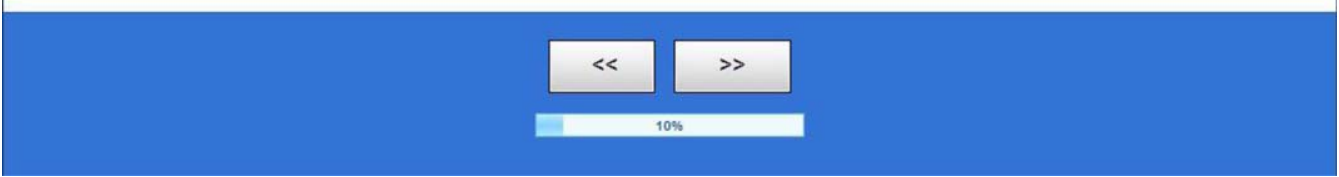

Fig. B1. . Screen shot of one choice question.

force all cutbacks initially to come from other sectors. So, the two options are "Exempt Transport" (Yes) or "Don't Exempt Transport" (No).

E. Special treatment for other sectors? There are proposals to give special treatment for the first three years to electric utilities, exporters who use lots of energy, and farmers, which would give them more time to adjust and reduce job disruption. A drawback of doing this is that it will force the rest of the economy to cut back more in the early years of a plan, which would return less money to households. So, the two options are "Special Treatment" (Yes) or "No Special Treatment" (No).Fig. B1

\section{References}

ABC NewsPoll, 2008. ABC News/Planet Green/Stanford University poll, 23-28 July 2008. Available on line at 〈www.pollingreport.com〉 in the energy section.

Bateman, I., Carson, R.T., Day, B., Hanemann, W.M., Hanley, N., Hett, T., Jones-Lee, M., Loomes, G., Mourato, S., Özdemiroglu, E., Pearce, D., Sugden, R., Swanson, J., 2002. In: Economic Valuation with Stated Preference Techniques: A Manual. Edward Elgar, Northampton, MA

Berrens, R.P., Bohara, A.K., Jenkins-Smith, H.C., Silva, C.L., Weimer, D.L., 2004. Information and effort in contingent valuation surveys: application to global climate change using national internet samples. Journal of Environmental Economics and Management 47, 331-363.

Berk, R.A., Fovell, R.G., 1999. Public perceptions of climate change: a "willingness to pay" assessment. Climatic Change 41, 413-446.

Berk, R.A., Schulman, D., 1995. Public perceptions of global warming. Climatic Change 29, 1-33.

BBC, 2007. Most would pay higher energy bills to address climate change—global poll. BBC World Service Poll/Global Scan/PIPA, 7 November.

Box, G.E.P., Hunter, W.G., Hunter, J.S., 1978. Statistics for experimenters: an introduction to design, Data Analysis and Model Building. John Wiley, New York.

Cameron, T.A., 2005a. Updating subjective risks in the presence of conflicting information: an application to climate change. Journal of Risk and Uncertainty $30,63-97$.

Cameron, T.A., 2005b. Individual option prices for climate change mitigation. Journal of Public Economics 89, 281-301.

Dunlap, R.E., 1998. Lay perceptions of global risk—public views of global warming in crossnational context. International Sociology 13, 473-498.

Firestone, J., Kempton, W., 2007. Public opinion about large offshore wind power: underlying factors. Energy Policy 35, 1584-1598.

Garnaut, R., 2008. Garnaut Climate Change Review: Final Report. Cambridge University Press, New York. Also available at: 〈http://www.garnautreview. org.au $>$.

Hersch, J., Viscusi, W.K., 2006. The generational divide in support for environmental policies: European evidence. Climatic Change 77, 121-136.

Kempton, W., 1991. Lay perspectives on global climate change. Global Environmental Change 1, 183-208.

Kopp, R.J., Portney, P.R., 1999. Mock referenda for intergenerational decisionmaking. In: Portney, P.R., Weyant, J. (Eds.), Discounting and Intergenerational Equity. Resources for the Future, Washington, DC, pp. 87-98.
Layton, D.F., Brown, G.M., 2000. Heterogeneous preferences regarding global environmental change. Review of Economics and Statistics 82, 616-624.

Lee, J.J., Cameron, T.A., 2008. Popular support for climate change mitigation: evidence from a general population mail survey. Environmental and Resource Economics 41, 223-248.

Lee, J.S., Yoo, S.H., Kwak, S.J., forthcoming. Public's willingness to pay for preventing climate change. Applied Economics Letters.

Louviere, J.J., Hensher, D.A., Swait, J.D., 2000. Stated Choice Methods: Analysis and Applications. Cambridge University Press, New York.

Opaluch, J.J., Swallow, S.K., Weaver, T., Wessells, C.W., Wichelns, D., 1993. Evaluating impacts from noxious facilities: including public preferences in siting mechanisms. Journal of Environmental Economics and Management 24, 41-59.

O'Connor, R.E., Bord, R.J., Fisher., A., 1999. Risk perceptions, environmental beliefs and willingness to address climate change? Risk Analysis 19, 461-471.

O'Connor, R.E., Bord, R.J., Yarnal, B., Yiefek, N., 2002. Who wants to reduce greenhouse gas emissions. Social Science Quarterly 83, 1-17.

Page, B.R., Shapiro, R.Y., 1983. Effects of public opinion on policy. American Political Science Review 77, 175-190.

PEW Research Center for People and the Press2008. A deeper partisan divide over global warming. Available at: 〈http://www.people-press.org/report/417/ a-deeper-partisan-divide-over-global-warming $\rangle$.

Read, D., Bostrom, A., Morgan, M.G., Fischhoff, B., Smuts, T., 1994. What do people know about global climate change?: 2. Surveys of educated lay people. Risk Analysis 14, 9-971-982.

Riera, P., Peñuelas, J", Farreras, V“, Estiarte, M“, 2007" Valuation of climate-change effects on Mediterranean shrublands. Ecological Applications 17, 91-100.

Stern, N., 2007. In: The Economics of Climate Change: the Stern Review. Cambridge University Press, New York.

Stewart, T.R., Gelherd, L., 1976. Analysis of judgment policy: a new approach to citizen participation in planning. Journal of the American Institute of Planners $42,33-41$.

Stimpson, J.A., Mackuen, M.B., Erikson, R.S., 1996. Dynamic representation. American Political Science Review 89, 543-565.

Street, D.J., Burgess, L., 2007. In: The Construction of Optimal Stated Choice Experiments: Theory and Methods. John Wiley, New York.

WorldPublicOpinion.org, 2008. In: World publics strongly favor requiring more wind and solar energy, energy efficiency even if it costs. Program on International Policy Attitudes (PIPA), University of Maryland.

Zahran, S., Brody, S.D., Grover, H., Vedlitz, A., 2006. Climate change vulnerability and policy support. Society and Natural Resources 19, 771-789. 